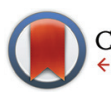

CrossMark \&lick for updates

Cite this: Org. Biomol. Chem., 2015, 13,3787

Received 26th December 2014, Accepted 5th February 2015

DOI: $10.1039 / c 4 o b 02671 c$

www.rsc.org/obc

\title{
Gold-catalyzed allene cycloisomerization for pyrrole synthesis: towards highly fluorinated BODIPY dyes $\uparrow$
}

\author{
Linda Lempke, ${ }^{a}$ Tobias Fischer, ${ }^{\text {b }}$ Jérémy Bell, ${ }^{\text {b } W e r n e r ~ K r a u s, ~}{ }^{\mathrm{b}}$ Knut Rurack* ${ }^{* \mathrm{~b}}$ and \\ Norbert Krause*a
}

\begin{abstract}
A novel synthetic strategy toward highly fluorinated BODIPY dyes with exceptional photostabilities relying on sustainable gold catalysis has been developed. A key to the tailored pyrrole precursors is the gold catalysis performed in ionic liquids as the reaction medium, allowing a facile recycling of the catalysts. The dyes prepared are well-matching with the spectral windows of popular rhodamine dyes and possess high brightness while showing a distinctly higher photostability than the rhodamines especially in aprotic solvents.
\end{abstract}

\section{Introduction}

Sustainable metal catalysis has attracted general attention during the last few years. Meanwhile also for gold catalysis powerful sustainable methods are known. ${ }^{1}$ The use of ionic liquids (ILs) or micelles as the reaction medium enables the stabilization of catalysts, preventing their undesired reduction to metallic gold. Previously, the unique stability and recyclability of these catalyst solutions were demonstrated. ${ }^{2}$

Novel sustainable synthetic routes are often a key to success in advancing compounds of a certain class of specialty chemicals, for instance with unprecedented substitution patterns or improved reaction yields. In this regard, boron-dipyrromethene (BODIPY) dyes as one of the fastest growing classes of dyes ${ }^{3}$ are very attractive targets. The popularity of BODIPY dyes is rooted in their outstanding absorption and fluorescence properties and high photo- and chemical stabilities, having resulted in a wide variety of applications. Besides bioimaging, ${ }^{4}$ fluorescent indicators, ${ }^{5}$ photodynamic therapy, ${ }^{6}$ and organic photovoltaics, ${ }^{7}$ highly fluorinated BODIPYs have been recently found to constitute a very promising class of multifunctional labeling agents. ${ }^{8}$ One of the bottlenecks for novel

${ }^{a}$ Organic Chemistry, Dortmund University of Technology, Otto-Hahn-Str. 6, D-44227 Dortmund, Germany.E-mail: norbert.krause@tu-dortmund.de; Fax: (+)49 2317553884

${ }^{b}$ Dept. 1 Analytical Chemistry; Reference Materials, BAM Federal Institute for Materials Research and Testing, Richard-Willstätter-Str. 11, D-12489 Berlin, Germany. E-mail: knut.rurack@bam.de; Fax: (+)49 3081041157

$\dagger$ Electronic supplementary information (ESI) available: Full experimental details, including X-ray structure analysis, optical spectroscopy, computational studies, and NMR spectra. CCDC 1040186 and 1040187. For ESI and crystallographic data in CIF or other electronic format see DOI: 10.1039/c4ob02671c
BODIPYs is the availability of tailor-made pyrroles which constitute their core building blocks.

The expertise of our groups in sustainable metal catalysis ${ }^{2}$ and the development of high-performance dyes ${ }^{9}$ prompted us to embark on a collaborative approach toward new fluorinated BODIPY dyes 4 by gold-catalyzed cycloisomerization of $\alpha$-aminoallenes 1 to 2,5-dihydropyrroles 2 in ionic liquids (Scheme 1). Although fluorinated BODIPYs possess many promising features, only a very limited number of fluorinated BODIPYs is known in the literature. ${ }^{8,10}$ Furthermore, the synthesis of pyrroles by cyclization reactions allows extensive structural variation and represents a valuable alternative compared to common strategies. ${ }^{11}$
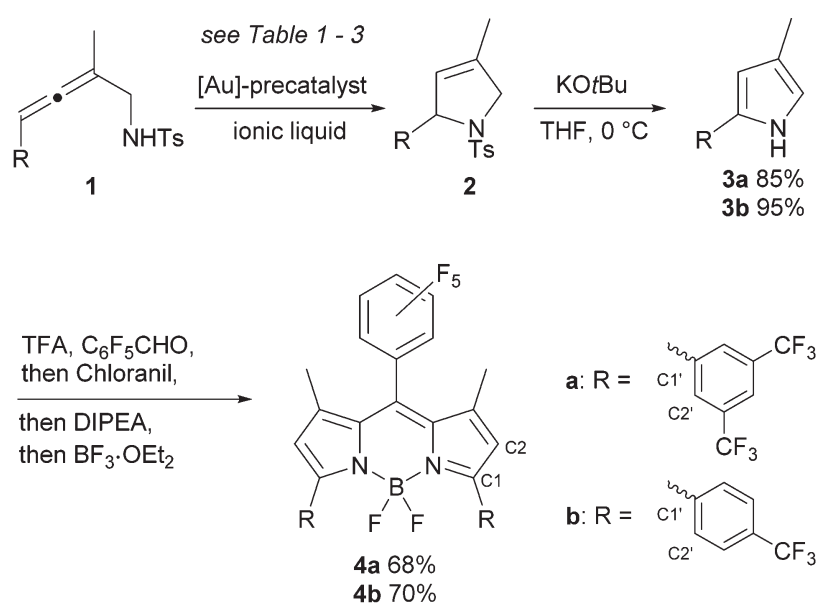

Scheme 1 Synthesis of BODIPY dyes. 


\section{Results and discussion}

The cycloisomerization was carried out in ionic liquids (Tables 1-3). Different gold catalysts and ionic liquids were examined for this purpose (Scheme 2).

The cyclization conditions were optimized with allene $\mathbf{1 a}$ and cationic gold catalyst $\mathbf{A}$ (Table 1). Best results were achieved with $[\mathrm{BMIM}]\left[\mathrm{PF}_{6}\right]$ and $[\mathrm{BMIM}]\left[\mathrm{HSO}_{4}\right]$.

With 1 mol\% of catalyst $\mathbf{A}$ in [BMIM] $\left[\mathrm{PF}_{6}\right]$, complete conversion was observed after $24 \mathrm{~h}$, while $2 \mathrm{~mol} \%$ led to a shorter reaction time of $2 \mathrm{~h}$ (entries $1 \& 2$ ). The acidic ILs [BMIM]$\left[\mathrm{HSO}_{4}\right]$ and $[\mathrm{EMIM}]\left[\mathrm{HSO}_{4}\right]$ were used at $60{ }^{\circ} \mathrm{C}$ to attain a lower

Table 1 Influence of ionic liquids on the gold-catalyzed cycloisomerization of $\alpha$-aminoallene 1 a

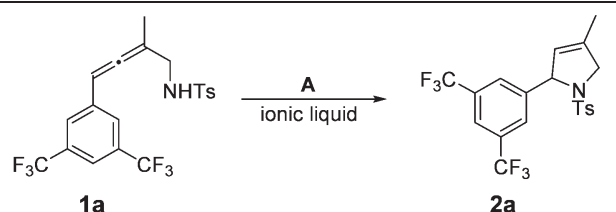

\begin{tabular}{|c|c|c|c|c|c|}
\hline Entry & Ionic liquid & $\mathbf{A}(\mathrm{mol} \%)$ & $T\left({ }^{\circ} \mathrm{C}\right)$ & $t(\mathrm{~h})$ & Conv. $^{a}(\%)$ \\
\hline 1 & {$[\mathrm{BMIM}]\left[\mathrm{PF}_{6}\right]$} & 1 & 25 & 24 & 100 \\
\hline 2 & {$[\mathrm{BMIM}]\left[\mathrm{PF}_{6}\right]$} & 2 & 25 & 2 & 100 \\
\hline 3 & {$[\mathrm{BMIM}]\left[\mathrm{PF}_{6}\right]$} & 2 & 60 & 0.25 & 100 \\
\hline 4 & {$[\mathrm{BMIM}]\left[\mathrm{HSO}_{4}\right]$} & 2 & 60 & 0.25 & 100 \\
\hline 5 & {$[\mathrm{EMIM}]\left[\mathrm{HSO}_{4}\right]$} & 2 & 60 & 1 & 100 \\
\hline 6 & {$[\mathrm{BMIM}]\left[\mathrm{HSO}_{4}\right]$} & - & 60 & 24 & 0 \\
\hline 7 & {$[\mathrm{EMIM}]\left[\mathrm{HSO}_{4}\right]$} & - & 60 & 24 & 0 \\
\hline 8 & {$[\mathrm{BMIM}]\left[\mathrm{BF}_{4}\right]$} & 2 & 25 & 24 & 0 \\
\hline 9 & {$[\mathrm{EMIM}]\left[\mathrm{BF}_{4}\right]$} & 2 & 25 & 24 & 0 \\
\hline
\end{tabular}

${ }^{a}$ Conversion was determined by ${ }^{1} \mathrm{H}-\mathrm{NMR}$ spectroscopy.

Table 2 Influence of the gold catalyst on the cycloisomerization of $\alpha$-aminoallene $1 \mathrm{a}$ in [BMIM] $\left[\mathrm{PF}_{6}\right]$

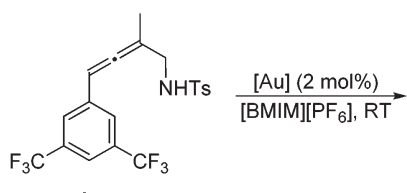

$1 a$

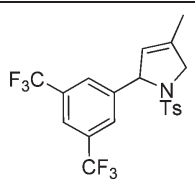

$2 a$

\begin{tabular}{llllr}
\hline Entry & {$[\mathrm{Au}]$} & Additive & $t$ & Conv. $^{a}(\%)$ \\
\hline 1 & $\mathbf{A}$ & - & $2 \mathrm{~h}$ & 100 \\
2 & $\mathrm{AuBr}_{3}$ & - & $48 \mathrm{~h}$ & 30 \\
3 & $\mathrm{Ph}_{3} \mathrm{PAuNTf}_{2}$ & - & $1 \mathrm{~h}$ & 100 \\
$4^{b}$ & $\mathrm{Ph}_{3} \mathrm{PAuNTf}_{2}$ & - & $5 \mathrm{~min}$ & 100 \\
5 & $\mathrm{Ph}_{3} \mathrm{PAuCl}$ & $\mathrm{AgSbF}_{6}$ & $1 \mathrm{~h}$ & 100 \\
6 & $\mathrm{Ph}{ }_{3} \mathrm{PAuCl}$ & - & $24 \mathrm{~h}$ & 0 \\
7 & $\mathbf{B}$ & $\mathrm{AgSbF}_{6}$ & $30 \mathrm{~min}$ & 100 \\
8 & $\mathbf{B}$ & - & $24 \mathrm{~h}$ & 0 \\
$9^{b}$ & $\mathbf{B}$ & $\mathrm{AgSbF}_{6}$ & $5 \mathrm{~min}$ & 100 \\
$10^{c}$ & $\mathbf{B}$ & $\mathrm{AgSbF}_{6}$ & $10 \mathrm{~min}$ & 100 \\
11 & - & $\mathrm{AgSbF}_{6}$ & $24 \mathrm{~h}$ & 20
\end{tabular}

${ }^{a}$ Conversion was determined by ${ }^{1} \mathrm{H}$-NMR spectroscopy. ${ }^{b}$ Toluene (ca. 20 vol\%) was added. ${ }^{c}$ Reaction temperature of $50{ }^{\circ} \mathrm{C}$.
Table 3 Recycling of the catalyst/solvent system

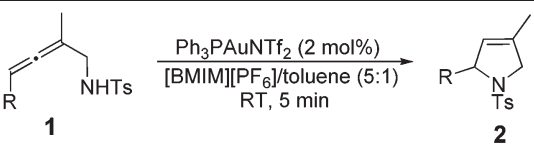

\begin{tabular}{llll}
\hline Entry & Allene & Run & Yield $^{a}(\%)$ \\
\hline 1 & $\mathbf{1 a}$ & 1 & 91 \\
2 & $\mathbf{1 a}$ & 2 & 91 \\
3 & $\mathbf{1 a}$ & 3 & 98 \\
4 & $\mathbf{1 a}$ & 4 & 95 \\
5 & $\mathbf{1 a}$ & 5 & $80^{b}$ \\
6 & $\mathbf{1 b}$ & 1 & 90 \\
7 & $\mathbf{1 b}$ & 2 & 92 \\
${ }^{a}$ Isolated yield. $^{b}{ }^{12} \%$ of 1a was recovered.
\end{tabular}

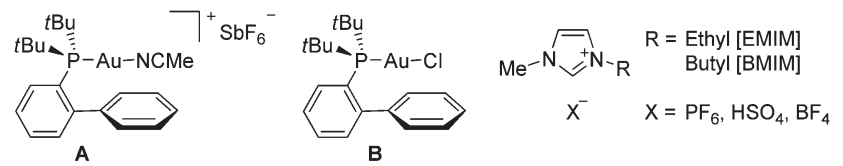

Scheme 2 Gold catalysts and ionic liquids used in this work.

viscosity. Short reaction times of $15 \mathrm{~min}$ and $1 \mathrm{~h}$ were obtained (entries 4 \& 5), which are comparable to $[\mathrm{BMIM}]\left[\mathrm{PF}_{6}\right]$ at the same temperature (entry 3). The acidic ILs do not mediate the cycloisomerization in the absence of the gold catalyst (entries 6 \& 7). ${ }^{12,13}$ In $[\mathrm{BMIM}]\left[\mathrm{BF}_{4}\right]$ and $[\mathrm{EMIM}]\left[\mathrm{BF}_{4}\right]$ no reaction was observed after $24 \mathrm{~h}$ at RT (entries $8 \& 9$ ). This may be due to a limited solubility of the gold catalyst in these more hydrophilic ionic liquids.

Allene 1a and ionic liquid $[\mathrm{BMIM}]\left[\mathrm{PF}_{6}\right]$ were used for screening the gold catalyst (Table 2). Except for $\mathrm{AuBr}_{3}$ (entry 2), all catalysts examined gave short reaction times between $30 \mathrm{~min}$ and $2 \mathrm{~h}$ (entries 1, 3, 5 \& 7). Both precatalyst $\mathbf{B}$ and $\mathrm{Ph}_{3} \mathrm{PAuCl}$ were transformed into the corresponding cationic gold species with $\mathrm{AgSbF}_{6}$. Without the addition of a silver salt no reaction was observed (entries 6 \& 8), whereas the silver salt alone induces only a very slow cyclization (entry 11). Beside the possibility of warming up (entry 10), the addition of a certain amount of toluene to form a solvent film led to decreased reaction times of 5 min (entries 4 vs. 3, 9 vs. 7). This acceleration is probably caused by the two-phasic character of the reaction mixture. While the catalyst/solvent system is a viscous solution, the allene is a solid and affords an emulsion during the reaction. The toluene seems to act as a phase-transfer agent. These conditions were chosen for recycling experiments (Table 3).

Previous investigations with $\mathrm{AuBr}_{3}$ in $[\mathrm{BMIM}]\left[\mathrm{PF}_{6}\right]$ showed an extremely low catalyst leaching using hexane as an extraction solvent. ${ }^{2 a}$ The pyrrolines 2 are not soluble in nonpolar solvents like hexane. Unfortunately, polar solvents like $\mathrm{Et}_{2} \mathrm{O}$ cause a dramatic catalyst leaching. Therefore, the recycling was tested for 1a with toluene as the extraction solvent and $\mathrm{Ph}_{3}$ PAuNTf $_{2}$ as the gold catalyst. Excellent reactivity was 


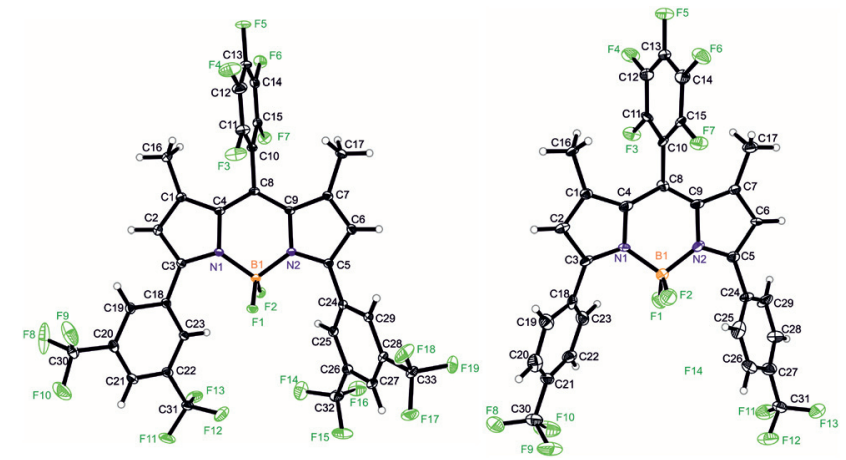

Fig. 1 ORTEP representation of $4 \mathrm{a}$ (left) and $4 \mathrm{~b}$ (right) with atomic labeling shown with $30 \%$ probability displacement ellipsoids.

observed over four runs (Table 3, entries 1-4). In all runs, the reactions were stopped after $5 \mathrm{~min}$, leading to quantitative conversions and high yields. A loss of reactivity was observed in the fifth run (entry 5), causing a lower yield of $80 \%$ (12\% of allene $\mathbf{1 a}$ were also recovered). Allene $\mathbf{1 b}$ was cyclized under similar conditions with $90 \%$ yield in 5 min (entry 6). A second run was carried out with a similar result (entry 7 ).

The cyclization products are converted into pyrroles using KOtBu in THF (Scheme 1). ${ }^{14}$ According to common strategies, these were directly used in the BODIPY synthesis. ${ }^{10 a}$ In contrast to the literature method, however, oxidation times were extended and a second complexation step was employed, finally providing the dyes in good yields of 68 and $70 \%$.

The molecular structures of $\mathbf{4 a}, \mathbf{b}$ were determined by singlecrystal X-ray diffraction analysis and the corresponding molecular configurations are shown in Fig. 1. Selected crystallographic data and structure refinement parameters are listed in Table S1. $\dagger$ The observed geometric parameters of all crystal structures are generally comparable to those of other BODIPYs. ${ }^{15} \mathbf{4 a}$ crystallizes in a monoclinic space group and $\mathbf{4 b}$ in a triclinic space group with similar crystal packing. There are no significant interactions like hydrogen bonds or $\pi-\pi$ interactions in the crystal lattice of both dyes. Only a weak $\pi-\pi$ interaction occurs in $\mathbf{4 a}$ with a plane-to-plane distance of $4.34 \AA$ between the same pyrrole rings $(\mathrm{N} 1, \mathrm{C} 1, \mathrm{C} 2$,C3, C4) of two neighbouring pyrromethene fragments of the BODIPY core.

The BODIPY skeleton formed by three conjugated heterocyclic rings is almost planar, with an rms deviation of 0.1260 and 0.1016 for $\mathbf{4 a}$ and $\mathbf{4 b}$. Due to steric repulsion of the methyl groups attached to $\mathrm{C} 1$ and $\mathrm{C} 7$, the pentafluorophenyl moiety is strongly twisted out of the BODIPY mean plane, with dihedral angles of $88.35(05)^{\circ}$ for $\mathbf{4 a}$ and $76.73(10)^{\circ}$ for $\mathbf{4 b}$, which is as expected more pronounced than for 1,7- $\mathrm{H}$ - and 3,5-diaryl-substituted dyes. ${ }^{10 \mathrm{e}, 15 c}$ An overlay of the two molecular configurations shows the differences in molecular conformation, i.e., the arrangement of the substituents attached at C3 and C5 (Fig. $\mathrm{S} 1 \dagger$ ). Whereas in $\mathbf{4 b}$ the two phenyl rings are almost parallel with a dihedral angle of $28.09(22)^{\circ}$, the angle amounts to $86.24(07)^{\circ}$ in 4 a. Because the arrangement of the molecules is head-to-tail, the short contacts from the pentafluorophenyl

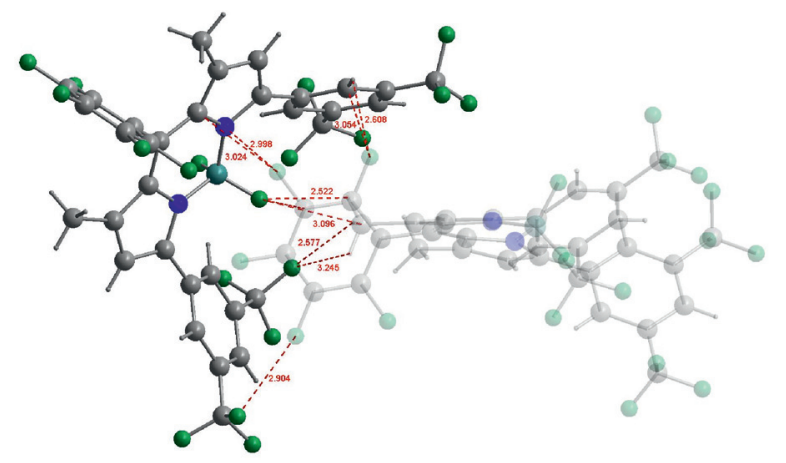

Fig. 2 Short contacts in 4 a lead to a bowl-like conformation.

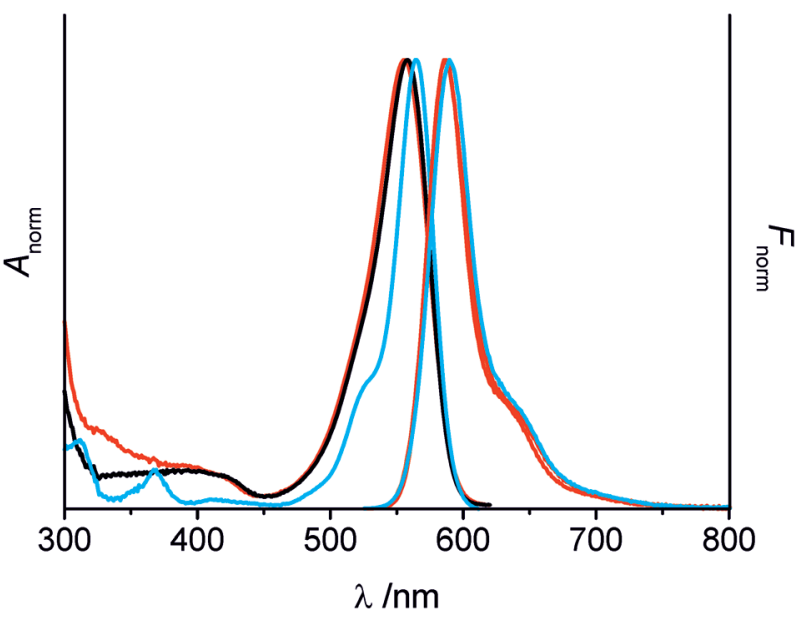

Fig. 3 Absorption and fluorescence spectra of $4 a$ (black) and $4 b$ (red) in ethanol; the corresponding spectra of rhodamine 101 (blue) are included for comparison.

ring to the phenyl rings at $\mathrm{C} 3,5$ lead to a bowl-like conformation of 4a (Fig. 2). Such a bowl-type arrangement of headto-tail aligned 3,5,8-phenyl-substituted BODIPYs has also been very recently reported by Wakamiya. ${ }^{15 c}$

The spectroscopic properties of $\mathbf{4 a}$ and $\mathbf{4 b}$ are comparable with very little dependence on the solvent. The spectral envelopes shown in Fig. 3 resemble classical BODIPY features. The high fluorescence quantum yields $\left(\Phi_{\mathrm{f}}>0.85\right)$, long fluorescence lifetimes $\left(\tau_{\mathrm{f}} \sim 5.5 \mathrm{~ns}\right)$ and high absorption coefficients $\left(\varepsilon_{\lambda \max } \sim 50000 \mathrm{M}^{-1} \mathrm{~cm}^{-1}\right)$, independent of solvent polarity and proticity, distinguish the dyes as bright emitters (comprehensive spectroscopic data of $\mathbf{4 a , b}$ are shown in the ESI $\dagger$ ). Compared to their parent dye, 8-pentafluorophenyl-1,7,3,5tetramethyl-BODIPY that carries methyl groups instead of the trifluoromethylphenyl residues on the 3,5 -positions, ${ }^{8}$ the absorption maxima are shifted by $c a .40 \mathrm{~nm}$ and the absorption bands are significantly broadened. The Stokes shifts are increased from $c a$. 300 to $1000 \mathrm{~cm}^{-1}$. In view of the color rules for BODIPY $\pi$-system substitution, ${ }^{16}$ these changes can be attributed to the extension of the fluorophores' $\pi$-system with the additional trifluorophenyl moieties and their enhanced 
rotational freedom. The comparatively small spectral differences between $\mathbf{4 a}$ and $\mathbf{4 b}$ despite the introduction of two additional $\mathrm{CF}_{3}$ groups in the first one are tentatively ascribed to the enhanced steric hindrance in the case of 3,5-phenyl substitution on the BODIPY core. ${ }^{17}$ That results in considerable (average) torsion angles around the $\mathrm{C} 1-\mathrm{C} 1^{\prime}$ bond $\left\langle\theta_{\mathrm{C} 2-\mathrm{C} 1-\mathrm{C}^{\prime}-\mathrm{C} 2^{\prime}}\right\rangle=$ $39^{\circ}$ for $\mathbf{4 a}$ and $38^{\circ}$ for $\mathbf{4 b}$ (for the atom numbering pattern, see Scheme 1, bottom panel) and hence reduced electronic coupling between the BODIPY core and phenyl rings, diminishing the electron withdrawing effect of these substituents. These experimental findings are well reflected by quantum chemical calculations employing the density functional theory (DFT) method, revealing differences in the $S_{1} \leftarrow S_{0}$ transition in the gas phase of only ca. $5 \mathrm{~nm}$ (Table S2, ESI $\dagger$ ). The latter are also the only oscillator-strong transitions in the $350-500 \mathrm{~nm}$ region for both dyes, involving HOMO and LUMO which are both centered almost exclusively on the 3,5-diphenyl-dipyrrin fragments for $\mathbf{4 a}, \mathbf{b}$ (Fig. S2, ESI $\dagger$ ). Furthermore, with the corresponding triplet transitions being shifted for $c a .1 .25 \mathrm{eV}$, the theoretical studies fully support the favorable spectroscopic properties found experimentally.

Dyes $\mathbf{4 a}$ and $\mathbf{4 b}$ absorb and emit in the green visible range, matching well the spectral region of prominent rhodamine dyes such as rhodamine $101,6 \mathrm{G}, \mathrm{B}$ or TRITC $^{18}$ and fitting perfectly to the output of green laser sources (e.g., the prominent 532 or $543 \mathrm{~nm}$ lasers, Fig. 3). Compared to rhodamines the zwitterionic yet net uncharged BODIPYs are commonly well soluble in organic solvents across the entire polarity range, ${ }^{3,19}$ broadening the areas of applications and offering potent alternatives to the search for hydrophobic rhodamine derivatives. $^{20}$ The most important feature of the newly synthesized fluorinated BODIPYs $\mathbf{4 a , b}$ with regard to application is their excellent photostability, in particular when used in aprotic solvents. Fig. 4 exemplarily combines the photobleaching curves of $\mathbf{4 a , b}$ and rhodamine 101 upon irradiation at $532 \mathrm{~nm}$.

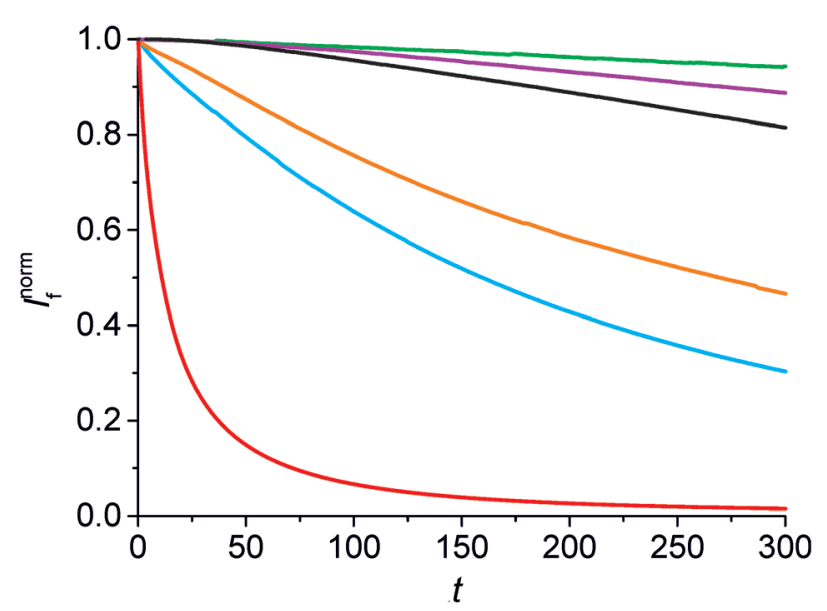

Fig. 4 Photobleaching curves for irradiation at $532 \mathrm{~nm}$ (1 W laser power) in acetonitrile (4a: orange, $4 \mathrm{~b}$ : blue, rhodamine 101: red) and ethanol (4a: magenta, 4b: green, rhodamine 101: black).

\section{Conclusions}

In the work presented here, two highly fluorinated and photostable BODIPY dyes with excellent spectroscopic properties have been prepared via gold catalysis in ionic liquids. While the use of sustainable gold catalysis is often strictly limited to the applied system, the possibility of recycling the catalyst solution was extended to more challenging allenes. Here, [BMIM $]\left[\mathrm{PF}_{6}\right]$ was found to be an excellent solvent system for gold catalysis and recycling. The fluorinated dyes possess an enormous potential for further applications such as functional group labeling or the staining of lipophilic compartments, for instance in cell imaging. Current work in our laboratories is directed toward both the synthesis of other functional BODIPYs and the application of the title dyes.

\section{Acknowledgements}

Financial support by SusChemSys (which is co-financed by the Regional Development Fund (Investing in Your Future) of the European Union and the state of North Rhine-Westphalia), the European Metrology Research Programme (EMRP) (project IND15 SurfChem) and the Adolf-Martens-Fund is gratefully acknowledged. The EMRP is jointly funded by the EMRP participating countries within EURAMET and the European Union.

\section{Notes and references}

1 (a) X. Liu, L. He, Y.-M. Liu and Y. Cao, Acc. Chem. Res., 2014, 47, 793; (b) C. Winter and N. Krause, Green Chem., 2009, 11, 1309; (c) C. Hviid Christensen and J. K. Nørskov, Science, 2010, 327, 278.

2 (a) Ö. Aksın and N. Krause, Adv. Synth. Catal., 2008, 350, 1106; (b) S. R. K. Minkler, B. H. Lipshutz and N. Krause, Angew. Chem., Int. Ed., 2011, 50, 7820; (c) S. R. K. Minkler, N. A. Isley, D. J. Lippincott, N. Krause and B. H. Lipshutz, Org. Lett., 2014, 16, 724; (d) X. Liu, Z. Pan, X. Shu, X. Duan and Y. Liang, Synlett, 2006, 1962; (e) X. Moreau, A. Hours, L. Fensterbank, J.-P. Goddard, M. Malacria and S. Thorimbert, J. Organomet. Chem., 2009, 594, 561.

3 (a) G. Ulrich, R. Ziessel and A. Harriman, Angew. Chem. Int. Ed., 2008, 47, 1184; (b) A. Loudet and K. Burgess, Chem. Rev., 2007, 107, 4891.

4 K. Umezawa, D. Citterio and K. Suzuki, Anal. Sci., 2014, 30, 327.

5 N. Boens, V. Leen and W. Dehaen, Chem. Soc. Rev., 2012, 41, 1130.

6 A. Kamkaew, S. H. Lim, H. B. Lee, L. V. Kiew, L. Y. Chung and K. Burgess, Chem. Soc. Rev., 2013, 42, 77.

7 A. Bessette and G. S. Hanan, Chem. Soc. Rev., 2014, 43, 3342.

8 (a) M. Hecht, T. Fischer, P. Dietrich, W. Kraus, A. Descalzo, W. Unger and K. Rurack, ChemistryOpen, 2013, 2, 25; (b) T. Fischer, P. M. Dietrich, C. Streeck, S. Ray, A. Nutsch, 
A. Shard, B. Beckhoff, W. E. S. Unger and K. Rurack, Anal. Chem., 2015, DOI: 10.1021/ac503850f.

9 (a) P. Ashokkumar, H. Weißhoff, W. Kraus and K. Rurack, Angew. Chem. Int. Ed., 2014, 53, 2225; (b) Y.-H. Yu, A. B. Descalzo, Z. Shen, H. Röhr, Q. Liu, Y.-W. Wang, M. Spieles, Y.-Z. Li, K. Rurack and X.-Z. You, Chem. - Asian J., 2006, 1, 176; (c) M. Kollmannsberger, K. Rurack, U. Resch-Genger and J. Daub, J. Phys. Chem. A, 1998, 102, 10211.

10 For pentafluorophenyl-substituted BODIPYs see: (a) G. Vives, C. Giansante, R. Bofinger, G. Raffy, A. Del Guerzo, B. Kauffmann, P. Batat, G. Jonusauskas and N. D. McClenaghan, Chem. Commun., 2011, 47, 10425; (b) O. Galangau, C. Dumas-Verdes, R. Méallet-Renault and G. Clavier, Org. Biomol. Chem., 2010, 8, 4546. For aryl- and fluorine-substituted BODIPYs see: (c) V. Lakshmi and M. Ravikanth, Chem. Phys. Lett., 2013, 564, 93; (d) V. Lakshmi and M. Ravikanth, J. Org. Chem., 2011, 76, 8466; (e) A. Burghart, H. Kim, M. B. Welch, L. H. Thoresen, J. Reibenspies and K. Burgess, J. Org. Chem., 1999, 64, 7813; $(f)$ L. H. Thoresen, H. Kim, M. B. Welch, A. Burghart and K. Burgess, Synlett, 1998, 11, 1276.

11 (a) V. Estévez, M. Villacampa and J. C. Menéndez, Chem. Soc. Rev., 2010, 39, 4402; (b) V. Estévez, M. Villacampa and J. C. Menéndez, Chem. Soc. Rev., 2014, 43, 4633. For 2,4substituted pyrroles see: (c) Z. Chen, B. Lu, Z. Ding, K. Gao and N. Yoshikai, Org. Lett., 2013, 15, 1966; (d) H.-Y. Wang, D. S. Mueller, R. M. Sachwani, H. N. Londino and L. L. Anderson, Org. Lett., 2010, 12, 2290-2293; (e) L. Meng, K. Wu, C. Liua and A. Lei, Chem. Commun., 2013, 49, 5853; (f) Z. Shi, M. Suri and F. Glorius, Angew. Chem., Int. Ed., 2013, 52, 4892.

12 N. Krause, M. Laux and A. Hoffmann-Röder, Tetrahedron Lett., 2000, 41, 9613.
13 N. Krause, A. Hoffmann-Röder and J. Canisius, Synthesis, 2012, 12, 1759.

14 T. Xu, X. Mu, H. Peng and G. Liu, Angew. Chem., Int. Ed., 2011, 50, 8176.

15 (a) C. L. Picou, E. D. Stevens, M. Shah and J. H. Boyer, Acta Crystallogr., Sect. C: Cryst. Struct. Commun., 1990, 46, 1148; (b) D.-C. Wang, C. He, J.-L. Fan, W.-W. Huang and X.-J. Peng, Acta Crystallogr., Sect. E: Struct. Rep. Online, 2007, 63, o2900; (c) A. Wakamiya, T. Murakami and S. Yamaguchi, Chem. Sci., 2013, 4, 1002.

16 Y.-W. Wang, A. B. Descalzo, Z. Shen, X.-Z. You and K. Rurack, Chem. - Eur. J., 2010, 16, 2887.

17 In addition it has to be kept in mind that the phenyl ring attenuates the effects of a $\mathrm{CF}_{3}$ group, i.e., the step from 4- $\mathrm{CF}_{3} \mathrm{C}_{6} \mathrm{H}_{5}$ to 3,5- $\left(\mathrm{CF}_{3}\right)_{2} \mathrm{C}_{6} \mathrm{H}_{4}$ has much less influence in terms of for instance the Hammett constant than the step from a $p-\mathrm{CF}_{3}$ to two $m-\mathrm{CF}_{3}$ groups, $c f$. e.g. G. A. Olah, A. L. Berrier, M. Arvanaghi and G. K. S. Prakash, J. Am. Chem. Soc., 1981, 103, 1122; Y. Borguet, X. Sauvage, G. Zaragoza, A. Demonceau and L. Delaude, Organometallics, 2010, 29, 6675.

18 (a) P. C. Beaumont, D. G. Johnson and B. J. Parsons, J. Chem. Soc., Faraday Trans., 1993, 89, 4185; (b) H. Brismar, O. Trepte and B. Ulfhake, J. Histochem. Cytochem., 1995, 43, 699.

19 Another advantage of BODIPY dyes is the straightforwardness of tailoring water solubility through substitution of the fluorine atoms of the $\mathrm{BF}_{2}$ group, see, e.g: (a) A. M. Courtis, S. A. Santos, Y. Guan, J. A. Hendricks, B. Ghosh, D. M. Szantai-Kis, S. A. Reis, J. V. Shah and R. Mazitschek, Bioconjugate Chem., 2014, 25, 1043; (b) S.-L. Niu, G. Ulrich, P. Retailleau, J. Harrowfield and R. Ziessel, Tetrahedron Lett., 2009, 50, 3840.

20 L. F. Mottram, S. Forbes, B. D. Ackley and B. R. Peterson, Beilstein J. Org. Chem., 2012, 8, 2156. 